\title{
Effects of gold, dapsone, and prednisone on serum C-reactive protein and haptoglobin and the erythrocyte sedimentation rate in rheumatoid arthritis
}

\author{
BRIAN MCCONKEY, PAUL DAVIES, R. A. CROCKSON, \\ A. P. CROCKSON, M. BUTLER, T. J. CONSTABLE, AND R. S. AMOS
}

From the Dudley Road Hospital and the Departments of Experimental Pathology and Mathematical Statistics, Birmingham University

SUMMARY Sequential measurements of serum C-reactive protein (CRP), serum haptoglobin (Hp), and erythrocyte sedimentation rate (ESR) were made in 209 patients with rheumatoid arthritis (RA); 78 of them were treated with gold, 71 with dapsone, and 60 with prednisone. The results were expressed as proportional changes in the measurements at 28-day intervals after treatment began. The period of study was 140 days. During treatment with gold and dapsone there were statistically significant gradual and progressive falls of similar magnitude in serum CRP and ESR. During treatment with prednisone serum CRP and ESR fell abruptly by 28 days and thereafter altered little. At 140 days prednisone had had the largest proportional effect on both measurements. During gold treatment the fall in serum $\mathrm{Hp}$ was similar to that of the ESR. In contrast, prednisone had little effect on Hp levels despite large falls in serum CRP and the ESR. Either prednisone stimulates Hp synthesis or the divergence is an expression of the difference in type of effect between gold and prednisone on RA. The effect of dapsone on serum Hp was large and progressive; it partly reflects haemolysis and, since the haemolysis was not progressive, partly improvement in the RA. The results show the relative efficacy of the drugs and suggest that dapsone may he a useful alternative treatment for RA.

We have discussed previously the use of sequential measurements of serum C-reactive protein (CRP) and haptoglobin (Hp) and of the erythrocyte sedimentation rate (ESR) in the management of patients with rheumatoid arthritis (RA) and the desirability of developing drugs with the capacity for lowering values of these measurements (McConkey et al., 1972; McConkey et al., 1973; Constable et al., 1975; McConkey, 1976; Amos et al., 1977). The magnitude of the effect of a drug on serum CRP, Hp, and the ESR can be regarded as a measure of its efficacy in a particular sense. The information provides a guide to how well the disease rather than just symptoms is controlled. The purpose of the present investigation was to study and compare the effects of treatment with gold, dapsone, or prednisone. We describe a method of

Accepted for publication 19 May 1978

Correspondence to Dr B. McConkey, Dudley Road Hospital, Dudley Road, Birmingham B18 7QH. expressing the results which allows direct comparisons between groups of patients and provides a numerical value signifying magnitude of effect.

\section{Patients and methods}

All patients had definite or classical RA (American Rheumatism Association criteria). They were seen at 2-8-week intervals. Initial treatment was with nonsteroid anti-inflammatory drugs. If active RA persisted, as judged by clinical evidence and consistently raised serum CRP, Hp, and ESR levels, patients were then also given either gold (sodium aurothiomaleate (Myocrisin) $50 \mathrm{mg}$ weekly, 78 patients), dapsone (dapsone $50 \mathrm{mg}$ daily for 1 week, then $100 \mathrm{mg}$ daily, 71 patients), or prednisone (prednisone $15 \mathrm{mg}$ daily for 2 weeks then $10 \mathrm{mg}$ daily, 60 patients). Prednisone was given to patients with more severe disease or when for some particular reason a rapid response was especially desirable. 
The majority of patients given gold were seen early in the study. Latterly we gave dapsone as an alternative, sometimes to patients who had not previously benefited from gold.

At each visit we made measurements of serum CRP (Mancini et al., 1965) using a standard which gives results approximately double those obtained with commercially available standards, serum $\mathrm{Hp}$ as haemoglobin binding capacity (Ratcliff and Hardwicke, 1964), and the ESR (Westergren).

\section{DATA HANDLING}

Differences between the mean values of the measurements in the 3 groups at the start of treatment presented difficulties in making comparisons. Moreover, the tendency for individuals with the highest initial values to show the largest falls is not clearly evident when results are expressed as changes in the means and could bias comparisons between treatments. We therefore explored an alternative method. We first considered all patients who attended at the arbitrarily chosen time of $140 \pm 14$ days after gold was begun. The relationship between the initial value for serum CRP and the change from that value seemed roughly linear. Using standard least squares methods, and the fact that there were clusters of patients with the same initial values, we confirmed that the relationship for these data was adequately represented by a straight line through the origin (Bliss, 1967; Butler, 1975). The slope of the line, which is the proportional change from the initial value, could therefore be used as a measure of the effect of gold ('treatment effect') on serum CRP at 140 days. Similarly treatment effects of gold on serum $\mathrm{Hp}$ and the ESR at 140 days were calculated, and the method was applied to other time periods and the other drugs.

\section{Results}

The three groups of patients were roughly similar in mean age, duration of RA, the proportion with a positive Rose-Waaler (RW) test, and in their mean RW titre (Table 1). The group given prednisone differed from the other 2 groups in having a muce higher mean serum CRP.

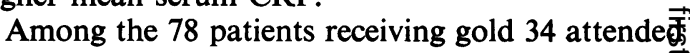
at $140 \pm 14$ days; the relationship between initidf serum CRP and the change in value at 140 days wase approximately linear (Fig. 1). The slope of the lin $\overline{\bar{\theta}}$ ('treatment effect') was -0.574 , signifying that i these patients values for serum CRP had fallen oB average to about $43 \%$ of the starting level. The same tests and calculations were applied to other time periods for gold and for the other drugs (Table

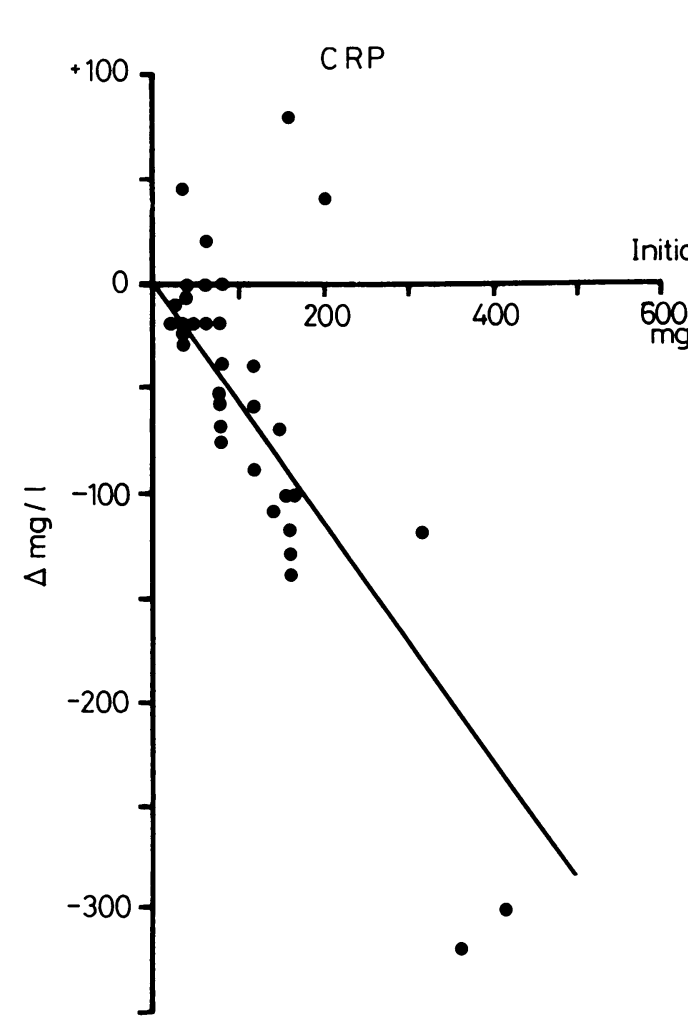

Fig. 1 Relationship between initial serum CRP and difference at $140 \pm 14$ days in 34 patients treated with gold.

Table 1 Particulars of the 3 groups of patients

\begin{tabular}{|c|c|c|c|c|c|c|c|c|}
\hline Treatment & $\begin{array}{l}\text { No. of } \\
\text { patients }(F)\end{array}$ & $\begin{array}{l}\text { Mean } \\
\text { age } \\
\text { years }\end{array}$ & $\begin{array}{l}\text { Mean } \\
\text { duration } \\
\text { of } \boldsymbol{R A}\end{array}$ & $\begin{array}{l}R W \\
+ \text { no. }\end{array}$ & $\begin{array}{l}\text { Mean } R W^{*} \\
\text { tube no. } \pm \mathrm{SE}\end{array}$ & $\begin{array}{c}\text { Mean } C R P \\
m g / l \pm \mathrm{SE}\end{array}$ & $\begin{array}{l}\text { Mean } H p \dagger \\
m g / l \pm \mathrm{SE}\end{array}$ & $\begin{array}{l}\text { Mean ESR } \\
\mathrm{mm} / \mathrm{h} \pm \mathrm{SE}\end{array}$ \\
\hline $\begin{array}{l}\text { Gold } \\
\text { Prednisone } \\
\text { Dapsone }\end{array}$ & $\begin{array}{l}78(49) \\
60(34) \\
71(53)\end{array}$ & $\begin{array}{l}46 \\
51 \\
50\end{array}$ & $\begin{array}{l}5 \cdot 2 \\
5 \cdot 1 \\
6 \cdot 3\end{array}$ & $\begin{array}{l}60 \\
41 \\
51\end{array}$ & $\begin{array}{l}3 \cdot 9 \pm 0 \cdot 3 \\
4 \cdot 0 \pm 0 \cdot 3 \\
4 \cdot 3 \pm 0 \cdot 3\end{array}$ & $\begin{array}{l}126 \cdot 2 \pm 10 \cdot 8 \\
165 \cdot 1 \pm 15 \cdot 0 \\
111 \cdot 5 \pm 10 \cdot 5\end{array}$ & $\begin{array}{l}2140 \pm 80 \\
1990 \pm 124 \\
1780 \pm 74\end{array}$ & $\begin{array}{l}48 \cdot 1 \pm 3 \cdot 2 \\
52 \cdot 8 \pm 4 \cdot 8 \\
51 \cdot 5 \pm 3 \cdot 8\end{array}$ \\
\hline
\end{tabular}

* Rose-Waaler titre converted to tube numbers. Tube No. 4=1:64. †Hp measured as mg Hb binding capacity. 
Table 2 'Treatment effects'

\begin{tabular}{|c|c|c|c|c|c|c|c|c|}
\hline \multirow[t]{2}{*}{ Time : days } & \multirow[t]{2}{*}{ Treatment } & \multirow{2}{*}{$\begin{array}{l}\text { Sample } \\
\text { size }\end{array}$} & \multicolumn{2}{|l|}{$C R P$} & \multicolumn{2}{|l|}{$H p$} & \multicolumn{2}{|l|}{$E S R$} \\
\hline & & & $b \dagger$ & $S E(b)$ & $b$ & $S E(b)$ & $b$ & $S E(b)$ \\
\hline \multirow{3}{*}{$28 \pm 14$} & Gold & 50 & $-0 \cdot 244^{* * *}$ & 0.074 & $-0.095^{* *}$ & 0.033 & -0.099 & 0.051 \\
\hline & Prednisone & 46 & $-0 \cdot 540^{* * *}$ & 0.057 & $-0.192^{* * *}$ & 0.040 & $-0.429^{* * *}$ & 0.046 \\
\hline & Dapsone & 64 & $-0 \cdot 213^{* * *}$ & 0.044 & $-0.298^{* * *}$ & 0.048 & $-0 \cdot 124^{* * *}$ & 0.041 \\
\hline \multirow[t]{2}{*}{$56 \pm 14$} & Gold & 72 & $-0 \cdot 168^{* * *}$ & 0.053 & $-0 \cdot 125^{* * *}$ & 0.028 & $-0 \cdot 123^{* * *}$ & 0.034 \\
\hline & Prednisone & 48 & $-0.583^{* * *}$ & 0.056 & $-0 \cdot 168^{* * *}$ & 0.038 & $-0.564^{* * *}$ & 0.043 \\
\hline \multirow[t]{3}{*}{$84 \pm 14$} & Gold & 46 & $-0.334^{* * *}$ & 0.065 & $-0 \cdot 158^{* * *}$ & 0.035 & $-0 \cdot 210^{* * *}$ & 0.040 \\
\hline & Prednisone & 52 & $-0.606^{* * *}$ & 0.051 & $-0 \cdot 178^{* * *}$ & 0.049 & $-0.512^{* * *}$ & 0.057 \\
\hline & Dapsone & 67 & $-0.419^{* * *}$ & 0.035 & $-0 \cdot 570^{* * *}$ & 0.039 & $-0 \cdot 213^{* * *}$ & 0.036 \\
\hline \multirow[t]{3}{*}{$112 \pm 14$} & Gold & 45 & $-0.514^{* * *}$ & 0.058 & $-0 \cdot 302^{* * *}$ & 0.034 & $-0.403^{* * *}$ & 0.045 \\
\hline & Prednisone & 40 & $-0.619^{* * *}$ & 0.058 & $-0 \cdot 120$ & 0.065 & $-0.457^{* * *}$ & 0.050 \\
\hline & Dapsone & 56 & $-0.432 * * *$ & $0 \cdot 145$ & $-0.679 * * *$ & 0.034 & $-0.274^{* * * *}$ & 0.042 \\
\hline \multirow{3}{*}{$140 \pm 14$} & Gold & 34 & $-0.574^{* * *}$ & 0.063 & $-0 \cdot 275^{* * *}$ & 0.039 & $-0 \cdot 382^{* * *}$ & 0.055 \\
\hline & Prednisone & 34 & $-0.642^{* * * *}$ & 0.063 & $-0 \cdot 150^{*}$ & 0.064 & $-0.470^{* * *}$ & 0.061 \\
\hline & Dapsone & 54 & $-0.465^{* * *}$ & 0.045 & $-0.717^{* * *}$ & 0.032 & $-0 \cdot 296^{* * *}$ & 0.043 \\
\hline
\end{tabular}

tThe value ' $b$ ' is the slope of the line through the origin relating change from initial value to initial value.

Stars denote a slope significantly different from zero at $* P<0.05, * * P<0.01, * * * P<0.001$ probability level.

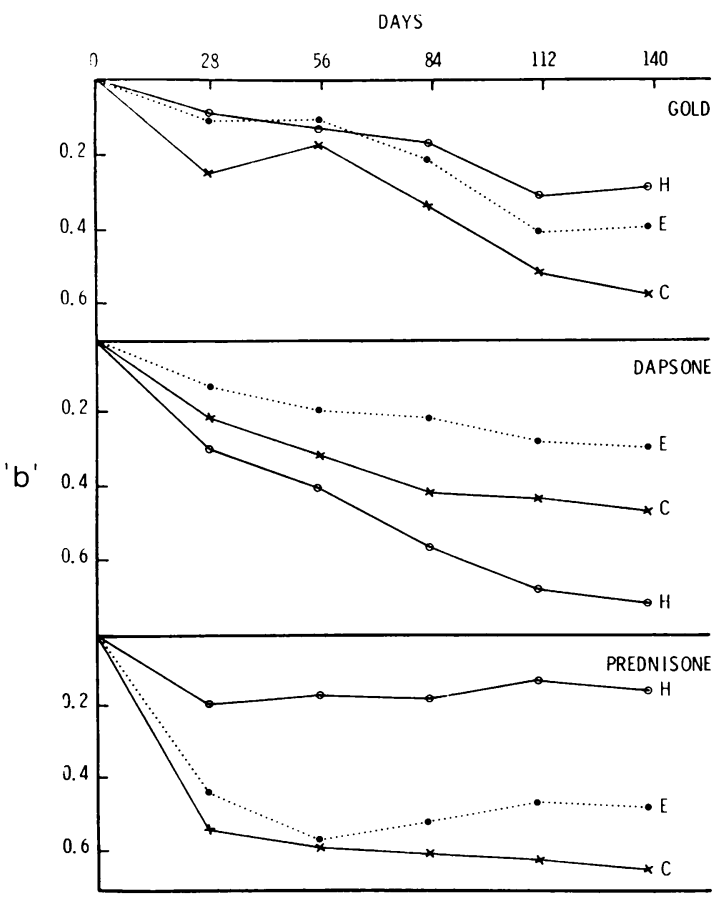

Fig. 2 Effects of gold, dapsone, and prednisone on $C R P, H p$, and ESR. ' $b$ '= the slope of the line calculated from data at each time interval.

Fig. 2). Fluctuating sample sizes were largely the consequence of irregular outpatient attendances.

During gold treatment there were statistically significant falls in serum CRP and $\mathrm{Hp}$ at 28 days and in ESR at 56 days; the values for each measurement continued to fall up to 140 days. During treatment with dapsone changes in CRP and ESR were similar to those with gold, though slightly smaller; there was a large fall in serum $\mathrm{Hp}$. During treatment with prednisone there were significant falls in all 3 measurements at 28 days; the falls in CRP and ESR were much larger than those resulting from gold or dapsone, but there was little further change after 56 days. The fall in $\mathrm{Hp}$ with prednisone at 28 days was not maintained, and by 112 and 140 days the change was smaller than at 28 days.

\section{Discussion}

By expressing the changes in the values of CRP, Hp, and ESR as the proportional fall from pretreatment levels we could make direct comparisons between the different drugs as well as between groups of patients.

In patients treated with gold an effect on CRP and $\mathrm{Hp}$, and to a less extent ESR, was discernible before clinical benefit could usually be recognised. The effect was greatest on CRP, which ultimately fell at 140 days to less than half the original value, but all 3 measurements showed substantial falls and were continuing to decline at the end of the study, suggesting that there was the likelihood of further improvement.

In patients treated with dapsone the changes in CRP and ESR were similar to those with gold, though at $\mathbf{1 4 0}$ days the effects of gold were slightly greater. Gold has been shown by controlled trials (Empire Research Council, 1960; Empire Research Council, 1961) to be effective in RA. The similarity between dapsone and gold in their effects on CRP and ESR in 2 reasonably well matched groups of patients suggests that dapsone may have a place in 
the treatment of this disease (McConkey et al., 1976). The effect of dapsone on $\mathrm{Hp}$ was large, presumably owing to slight haemolysis. Such an effect is unlikely to have influenced the falls in CRP or ESR even though $\mathrm{Hp}$ has an augmenting effect on ESR (Fischer and Gill, 1975), because some patients had large falls in $\mathrm{Hp}$ but no change in CRP or ESR. Moreover, the effect cannot be solely due to haemolysis, since haemoglobin falls within days of starting treatment by about $2 \mathrm{~g} / \mathrm{dl}$ and then usually remains constant, or occasionally rises.

Patients treated with prednisone had large changes in all 3 measurements at 28 days, consistent with the characteristic rapid clinical effect. However, though prednisone caused the largest falls in CRP and ESR initially, there was less difference between the 3 drugs by 140 days. The changes in CRP and ESR during prednisone treatment were roughly similar to each other; changes in $\mathrm{Hp}$, however, were much smaller and by 112 days values were little different from pretreatment levels. This divergence between $\mathrm{Hp}$ and CRP or ESR, the latter being largely a measure of fibrinogen (Hardwicke and Squire, 1952), could be explained by assuming either that prednisone preferentially increases $\mathrm{Hp}$ synthesis by the liver, or that the mechanism responsible for triggering the production of acute phase proteins involves more than one mediator, and that gold and prednisone act differently. The clinical significance of this divergence is uncertain, though a drug capable of lowering all 3 measurements is likely to be better than one which affects only 2 .

A number of patients stopped treatment during the study. Twenty-seven of the 78 patients given gold did so largely because of adverse effects; 11 of 71 patients stopped dapsone, usually because of inadequate effect. Thus, although the two drugs produced rather similar 'treatment effects', gold was more effective but also more toxic. Only 2 patients fell out of the prednisone group; this was because other therapy was added.

Each drug substantially lowered CRP to approximately half the initial values. Even so, mean CRP values in each group would on average have exceeded $40 \mathrm{mg} / \mathrm{l}$, and deterioration in their RA, judged radiographically, could still be expected though perhaps more slowly than before (Amos et al., 1977)

We thank the West Midlands Regional Health Authoris

We thank the West Midlands Regional Health Authorityo for financial support.

\section{References}

Amos, R. S., Constable, T. J., Crockson, R. A., Crockson $\overrightarrow{0}$ A. P. and McConkey, B. (1977). Rheumatoid arthritis:relation of serum C-reactive protein and erythrocyte sedimentation rate to radiographic changes. Britis/D Medical Journal, 1, 195-197.

Bliss, C. I. (1967). Statistics in Biology. McGraw Hill: New⿳亠丷厂 York.

Butler, M. (1975). A statistical study of the effects of 3 treat ments in rheumatoid arthritis. MSc thesis, University of Birmingham.

Constable, T. J., Crockson, R. A., Crockson, A. P., and McConkey, B. (1975). Drug treatment of rheumatois arthritis: a systematic approach. Lancet, 1, 1176-1180. $\rightarrow$

Empire Research Council (1960). Gold therapy in rheumatoid arthritis. Report of a multi-centre controlled trial. Annals. of the Rheumatic Diseases, 19, 95-119.

Empire Research Council (1961). Gold therapy in rheueo matoid arthritis. Final report of a multi-centre controlled trial. Annals of the Rheumatic Diseases, 20, 315-334.

Fischer, C. L., and Gill, C. W. (1975). 'Acute Phase Proteins? in Serum Protein Abnormalities: Diagnostic and Clinica Aspects, p. 331-350. Edited by S. E. Ritzmann and T. C? Daniels. Little, Brown: Boston.

Hardwicke, J., and Squire, J. R. (1952). Basis of erythrocytณ̊ sedimentation rate. Clinical Science, 2, 333-335.

McConkey, B. (1976). New drugs for inflammationclinical viewpoint for their assessment. Agents and Actions옹 6, 593-595.

McConkey, B., Davies, P., Crockson, R. A., Crockson, A. P Butler, M., and Constable, T. J. (1976). Dapsone in rheú matoid arthritis. Rheumatology and Rehabilitation, 15 230-234.

McConkey, B., Crockson, R. A., and Crockson, A. P. (1972) The assessment of rheumatoid arthritis. Quarterly Journa of Medicine, 41, 115-125.

McConkey, B., Crockson, R. A., Crockson, A. P., an£ Wilkinson, A. R. (1973). The effects of some anti-inflamb matory drugs on the acute-phase proteins in rheumatoid arthritis. Quarterly Journal of Medicine, 42, 785-791.

Mancini, G., Carbonata, A. O., and Heremans, J. F. (1965) Immunochemical quantitation of antigens by single radiat immunodiffusion. Immunochemistry, 2, 235-254.

Ratcliff, A. P., and Hardwicke, J. (1964). Estimation of seruro haemoglobin-binding capacity (haptoglobin) on Sephadex G 100. Journal of Clinical Pathology, 17, 676-679. 